Vol. 11 No. 012020

e-issn : 2622-0148, p-issn : 2087-0035

\title{
PENGARUH REBUSAN BUNGA ROSELLA (Hisbiscus sabdariffa) TERHADAP PENURUNAN TEKANAN DARAH PADA PENDERITA HIPERTENSI
}

The Influence of Rosella Stew (Hisbiscus sabdariffa) Towards Blood Preasure Degradation of Patients Patient With Hypertension

\author{
I Putu Artha Wijaya1', I Komang Widrma Atmaja'1, Kade Indah Sri \\ 'STIKES Bina Usada Bali \\ *) artha.wijaya001@gmail.com
}

\begin{abstract}
Introduction: Hypertension is a condition of increased blood pressure above normal which is $120 / 80 \mathrm{mmHg}$, this is a disease that is categorized as the silent killer disease, because many sufferers do not know that they have hypertension. Hypertension can be prevented by using non-pharmacological treatments is the stew of rosella flowers (hisbiscus sabdariffa) where rosella flowers can reduce blood pressure due to the presence of active ingredients namely anthocyanin, phenolic, threonine, leucine, valine, glycine and ascorbic acid. Objectives: to determine the effect of rosella stew (hisbiscus sabdariffa) on blood pressure in hypertensive patients in Sulangai Banjar, Sulangai Village. Method: This research was a pre-experimental study with one group pre-test and post-test design with sampling technique in this study using total sampling, the sampling technique where the number of samples was equal to the population of 33 people. Results: Wilcoxon Signed Rank Test analysis results obtained $p$ value $=0.001$ on the pre-test and post-test blood pressure which means the value of $p<0.05$ Conclusion: There was an Influence of Rosella (Hisbicus sabdariffa) Stew on Blood Pressure Decrease in Banjar Sulangai, Sulangai Village.
\end{abstract}

Keywords: rosella flower, hypertension, blood pressure

\begin{abstract}
ABSTRAK
Pendahuluan: Hipertensi merupakan suatu keadaan meningkatnya tekanan darah diatas normal yaitu 120/80 mmHg, hal ini merupakan penyakit yang dikategorikan sebagai the silent killer disease, karena banyak penderitanya yang tidak mengetahui dirinya mengidap penyakit hipertensi. Hipertensi dapat dicegah dengan menggunakan pengobatan non farmakologi yaitu rebusan bunga rosella (Hisbiscus sabdariffa) dimana bunga rosella ini dapat menurunkan tekanan darah karena adanya kandungan zat aktif yaitu Antosianin, Fenolik, Threonine, Leucine, Valine, Glycine dan Asam Askorbat. Tujuan: untuk mengetahui pengaruh rebusan bunga rosella (Hisbiscus sabdariffa) terhadap tekanan darah pada penderita hipertensi di Banjar Sulangai Desa Sulangai. Metode: Penelitian ini merupakan penelitian pra eksperimental dengan rancangan one group pre-post test dengan teknik pengambilan sampel dalam penelitian ini menggunakan total sampling yaitu dengan teknik pengambilan sampel dimana jumlah sampel sama dengan populasi yaitu 33 orang. Hasil: Hasil uji analisis Wilcoxon Signed Rank Test di dapatkan hasil nilai $p$ value $=0,001$ pada tekanan darah pre-test dan post-test yang artinya nilai $p<0,05$ Kesimpulan: Ada Pengaruh Rebusan Bunga Rosella (Hisbicus sabdariffa) Terhadap Penurunan Tekanan Darah di Banjar Sulangi, Desa Sulangi.
\end{abstract}

Kata kunci: bunga rosella, hipertensi, tekanan darah

\section{PENDAHULUAN}

Hipertensi sering disebut dengan peningkatan tekanan darah sistolik lebih dari 140 $\mathrm{mmHg}$ dan tekanan darah diastolik lebih dari 90 $\mathrm{mmHg}$. Hipertensi sering menyebabkan keadaan yang berbahaya, karena gejala yang ditimbulkan dari hipertensi tidak disadari dan kerap tidak menimbulkan keluhan bagi penderitanya (WHO, 2013). Gaya hidup yang tidak sehat seperti sering mengkonsumsi makanan berkadar garam yang tinggi, makanan siap saji (fast food) dan makanan yang berkolesterol dapat meningkatkan angka kejadian hipertensi. Kejadian hipertensi yang paling banyak dijumpai adalah hipertensi primer atau esensial yang tidak diketahui apa penyebabnya, faktor yang dapat mempengaruhi hipertensi primer atau esensial meliputi gaya hidup, merokok, kebiasaan mengkonsumsi alkohol yang berlebihan, stress, genetik atau keturunan, obesitas, kurang olahraga dan faktor usia (Indrayani, 2012).

Hipertensi dapat dikendalikan dengan cara mengubah gaya hidup seperti rutin berolahraga, berhenti merokok, menghindari minuman beralkohol, mengurangi konsumsi garam dan kafein serta pemberian obat anti hipertensi yang terbukti dapat menurunkan tekanan darah. Upaya lain yang dapat dilakukan untuk mengatasi penyakit hipertensi yaitu dengan pengobatan tradisional menggunakan rebusan bunga rosella. Pengobatan dengan menggunakan konsep back to nature dengan cara menggunakan bahan lokal. Pengobatan back to nature ini dimaksudkan kembali pengobatan dengan 
menggunakan bahan obat lokal alami yang ada di masyarakat dan bunga Rosella (hisbiscus sabdarifa) merupakan salah satu obat tradisional alternatif penurun tekanan darah. Senyawa aktif dalam rosella yang banyak berperan dalam menurunkan tekanan darah adalah antosianin, fenolik, theroine, leucine, valine, glycine dan asam askarbonat. Senyawa aktif yang terkandung dalam bunga rosella tersebut dapat membantu melancarkan peredaran darah dengan cara mengurangi derajat viskositas (kekentalan) darah, sehingga kerja jantung semakin ringan dan tekanan darah menjadi rendah (Haidar, 2016).

Tujuan dilakukan penelitian ini adalah untuk mengetahui Pengaruh Rebusan Bunga Rosella (Hisbiscus sabdariffa) Terhadap Tekanan Darah Pada Penderita Hipertensi di Banjar Sulangai, Desa Sulangai. Penelitian ini juga didukung dengan dengan jurnal yang ditulis oleh (Phinastika, 2011) tentang pengaruh seduhan kelopak kering bunga rosella (Hisbiscus sabdariffa) terhadap tekanan darah penderita prehipertensi dan hipertensi grade I yang diedukasi gaya hidup sehat terjadi penurunan tekanan darah setelah diedukasi gaya hidup sehat dan seduhan rosella selama 4 minggu dibandingkan dengan penurunan tekanan darah setelah diberikan edukasi gaya hidup saja.

Data yang diperoleh dari WHO (World Health Organization) tahun 2015 menunjukkan bahwa sekitar 1,13 miliar orang di dunia menyandang hipertensi, jumlah penyandang hipertensi terus meningkat setiap tahunnya, diperkirakan pada tahun 2025 akan ada 1,15 miliar orang yang terkena hipertensi dan diperkirakan setiap tahunnya 10,44 juta orang meninggal akibat hipertensi dan komplikasinya. Di Indonesia, berdasarkan Riskesdas 2018, prevalensi hipertensi berdasarkan hasil pengukuran pada penduduk usia 18 tahun sebesar $(34,1 \%)$, tertinggi di Kalimantan Selatan $(44,1 \%)$ sedangkan terendah di Papua sebesar (22,2\%). Hipertensi bisa terjadi pada kelompok umur 31-44 tahun $(31,6 \%)$, umur $45-54$ tahun $(45,3 \%)$, umur 55 64 tahun $(55,2 \%)$.

Data yang diperoleh dari Dinas Kesehatan Provinsi Bali, tahun 2016 berdasarkan pola 10 besar penyakit terbanyak pasien rawat jalan di puskesmas provinsi Bali tahun 2015 hipertensi menduduki peringkat ke-2. Total kasus hipertensi di Bali pada tahun 2014 adalah 114.21 kasus, dan tahun 2015 menjadi 89.394 kasus. Badung merupakan daerah yang sangat banyak dikunjungi wisatawan, dimana Kabupaten Badung memiliki jumlah penduduk diposisi ketiga dengan 656.900 ribu jiwa, kemudian Kabupaten Buleleng menduduki posisi kedua dengan 657.200 ribu jiwa dan Kota Denpasar yang menduduki posisi pertama dengan 930.600 ribu jiwa (Badan Pusat Statistik Provinsi Bali, 2018). Penyakit hipertensi di Rumah Sakit Mangusada Kabupaten
Badung ini pada tahun 2017 sebanyak 7.322 kasus atau sekitar 3,24 \%, dimana hipertensi masuk kedalam urutan kedua dari 10 besar penyakit di Rumah Sakit Mangusada Kabupaten Badung pada tahun 2017. Kecamatan Abiansemal Kabupaten Badung ini memiliki jumlah penduduk ketiga yang paling banyak dengan 83.579 ribu jiwa pada tahun 2011. Hipertensi masuk urutan kedua dari 10 besar penyakit di Puskesmas Abiansemal III dengan jumlah 167 kasus.

\section{METODE}

Penelitian ini dilakukan di Banjar Sulangai, Desa Sulangai mulai bulan Januari - Februari 2020. Penelitian ini merupakan penelitian pra eksperimental dengan rancangan one group pre-post test dimana ciri tipe penelitian ini adalah menggunakan hubungan sebab akibat dengan cara melibatkan suatu kelompok subjek. Pre-test dilakukan sebelum diberikan rebusan bunga rosella dan post-test dilakukan pada minggu ke 8 . Bahan rebusan yaitu 10 gr kelopak bunga rosella diseduh dalam $200 \mathrm{ml}$ air panas. Sampel dalam penelitian ini sebanyak 33 responden berusia 30-65 tahun yang menderita hipertensi dan mengkonsumsi obat Captopril, Teknik pengambilan sampel dalam penelitian ini menggunakan teknik total sampling yaitu teknik pengambilan sampel dimana jumlah sampel sama dengan populasi.

\section{HASIL}

\section{Gambaran Tekanan Darah Pre-Test}

Tabel 1. Gambaran Tekanan Darah Pre-Test

\begin{tabular}{lcc}
\hline $\begin{array}{l}\text { Tekanan Darah Pre- } \\
\text { Test }\end{array}$ & $\begin{array}{c}\text { Frekuensi } \\
\text { (f) }\end{array}$ & $\begin{array}{c}\text { Persentase } \\
(\%)\end{array}$ \\
\hline Optimal & $\cdot$ & $\cdot$ \\
Normal & $\cdot$ & $\cdot$ \\
Normal Tinggi & $\cdot$ & $\cdot$ \\
Hipertensi Derajat 1 & 12 & 36,3 \\
Hipertensi Derajat II & 19 & 57,6 \\
Hipertensi Derajat III & 2 & 6,1 \\
\hline Total & 33 & 100 \\
\hline
\end{tabular}

Tabel 1 menunjukkan bahwa kategori Tekanan Darah sebelum diberikan rebusan Bunga Rosella (Hisbicus sabdariffa) yaitu hipertensi derajat I berjumlah 12 responden (36,3\%), hipertensi derajat II berjumlah 19 responden $(57,6 \%)$ dan derajat III berjumlah 2 responden $(6,1 \%)$. 


\section{Gambaran Tekanan Darah Post-Test}

Tabel 2. Gambaran Tekanan Darah Post-Test

\begin{tabular}{lcc}
\hline $\begin{array}{l}\text { Tekanan Darah Post- } \\
\text { Test }\end{array}$ & $\begin{array}{c}\text { Frekuensi } \\
(\mathbf{f})\end{array}$ & $\begin{array}{c}\text { Persentase } \\
(\%)\end{array}$ \\
\hline Optimal & $\cdot$ & $\cdot$ \\
Normal & $\cdot$ & $\cdot$ \\
Normal Tinggi & $\cdot$ & $\cdot$ \\
Normal Tinggi & 10 & 30,3 \\
Hipertensi Derajat I & 23 & 69,7 \\
Hipertensi Derajat II & $\cdot$ & $\cdot$ \\
Hipertensi Derajat III & $\cdot$ & $\cdot$ \\
\hline Total & 33 & 100 \\
\hline
\end{tabular}

Tabel 2 menunjukkan bahwa kategori Tekanan Darah setelah diberikan Bunga Resella (Hisbicus sabdariffa) yaitu tekanan darah normal tinggi berjumlah 10 responden $(30,3 \%)$ dan hipertensi derajat I berjumlah 23 responden $(69,7 \%)$.

\section{Analisis Pengaruh Pemberian Pengaruh Rebusan Bunga Rosella (Hisbicus sabdariffa) Terhadap Penurunan Tekanan Darah}

Tabel 3. Hasil Analisis Wilcoxon Sign Rank Test

\begin{tabular}{|c|c|c|c|}
\hline \multirow{2}{*}{ Klarifikasi } & \multirow[t]{2}{*}{$\mathbf{N}$} & \multicolumn{2}{|c|}{$\begin{array}{c}\text { Tekanan Darah } \\
\text { (Pre-Test dan Post-Test) }\end{array}$} \\
\hline & & $\mathrm{P}$ & $\mathrm{Z}$ \\
\hline Pre & 33 & \multirow{2}{*}{0.001} & \multirow{2}{*}{-5.416} \\
\hline Post & 33 & & \\
\hline
\end{tabular}

Tabel 3 menunjukkan uji analisis menggunakan Wilcoxon Signed Rank Test di dapatkan hasil $p$ value $=0,001$ pada tekanan darah pre-test dan post-test yang artinya nilai $p<0,05$, artinya Ho ditolak dan Ha diterima, jadi dapat disimpulkan bahwa ada Pengaruh Rebusan Bunga Rosella (Hisbicus sabdariffa) Terhadap Penurunan Tekanan Darah Di Banjar Sulangi, Desa Sulangi.

\section{PEMBAHASAN}

Bunga rosella (Hibiscus sabdariffa) merupakan obat tradisional yang dapat menurunkan tekanan darah, pencegah kanker, meningkatkan sistem kekebalan tubuh dan sebagai antidiabetes (Haidar, 2016). Mekanisme dari bunga rosella (Hibiscus sabdariffa) dalam menurunkan tekanan darah karena mengandung zat antosianin yang memiliki kemampuan dalam mempertahankan elastisitas dinding pembuluh darah, semakin elastis dinding pembuluh darah maka akan menyebabkan tahanan sistemik semakin kecil. Dengan sedikitnya tahanan sistemik maka tubuh tidak membutuhkan tenaga atau tekanan yang tinggi untuk mengalirkan darah. Tekanan juga dapat dipengaruhi oleh jumlah volume cairan yang ada di dalam tubuh. Bunga rosella memiliki kandungan asam askabonat yang memiliki kemampuan sebagai diuritik, peningkatan ekskresi cairan tubuh yang disebabkan karena diuritik dapat menurunkan tekanan darah (Rohaendi, 2008).

Penelitian ini juga senada dengan penelitian yang dilakukan oleh oleh Putra (2013) tentang "Efektifitas Bunga Rosella Untuk Penurunan Tekanan Darah Pada Pasien Hipertensi di Desa Kedondong Kecamatan Kebonsari Kabupaten Madiun" juga menunjukkan bahwa ada pengaruh pemberian rebusan bunga rosella untuk penurunan tekanan darah tinggi.

\section{KESIMPULAN}

Rebusan Bunga Rosella (Hibiscus sabdariffa) dapat menurunkan Tekanan Darah pada penderita Hipertensi di Banjar Sulangi, Desa Sulangi. Penelitian ini diharapkan dapat digunakan oleh masyarakat khususnya masyarakat Banjar Sulangai Desa Sulangai yang memiliki tekanan darah tinggi untuk menggunakan pengobatan non farmakologi terlebih dahulu seperti rebusan bunga rosella (Hibiscus sabdariffa) sebelum menggunakan pengobatan farmakologi

\section{DAFTAR PUSTAKA}

Badan Pusat Statistik Provinsi Bali. (2018). Provinsi Bali Dalam Angka 2018. Denpasar: Badan Pusat Statistik Provinsi Bali.

Dinas Kesehatan Provinsi Bali. (2016). Profil Kesehatan Provinsi Bali tahun 2016. Bali: Dinas Kesehatan Provinsi Bali.

Haidar, Z. (2016). Si Cantik Rosella: Bunga Cantik Berjuta Khasiat. Jakarta: Edumania.

Rohaendi, H. (2008). Pengaruh Pemberian Teh Rosella Terhadap Tekanan Darah Pasien Hipertensi Primer di Panti Jompo Welas Asih Kota Tasikmalaya.Universitas Indonesia.

Indrayani. (2012). Gambaran tekanan darah pada gagal ginjal kronik intra hemodialis di ruang hemodialisa RSUP Sanglah Denpasar. Universitas Udayana.

Putra, H. A. (2013). Efektifitas Bunga Rosella Untuk Penurunan Tekanan Darah Pada Pasien Hipertensi di Desa Kedondong Kecamatan Kebonsari Kabupaten Madiun. Universitas Muhammadiyah Ponorogo.

Pinasthika, G. (2011). Pengaruh pemberian seduhan kelopak kering bunga rosella (Hibiscus sabdariffa) terhadap tekanan darah penderita prehipertensi dan hipertensi grade 1 yang diedukasi gaya hidup sehat. Universitas 
Jurnal Media Keperawatan: Politeknik Kesehatan Makassar

Vol.11 No. 012020

e-issn : 2622-0148, p-issn : 2087-0035

Diponegoro

WHO. (2013). A Global Brief On Hypertension. Silent Killer, global public health crisi.http://ishword.com/downloads/pdf/global_brief_hypertension.pdf

WHO. (2015). Kementerian Republik Indonesia. http://www.depkes.go.id/article/view/19051700002/hipertensipenyakit-palling-banyak-diidap-masyarakat.html

Yunita. (2017). Berdamai Dengan Hipertensi. Jakarta: Bumi Medika. 